\title{
EL MONÓLOGO DRAMÁ
EN LA ANTIPOESÍA DE NICANOR PARRA
}

\author{
THE DRAMATIC MONOLOGUE IN \\ THE ANTIPOETRY OF NICANOR PARRA
}

\section{MARLENE GOTTLIEB*}

\section{RESUMEN}

El monólogo dramático, un género literario desarrollado en el siglo XIX por los poetas ingleses Robert Browning y Alfred Tennyson, sigue vigente en la antipoesía de Nicanor Parra donde resaltan sus aportes más marcados: la apertura de la poesía al lenguaje hablado cotidiano y a la actualidad; la claridad sintáctica y lexica; la sustitución del sujeto lírico romántico por un personaje que cada vez más se va alejando del yo empírico del poeta; la incorporación de distintos discursos lingüísticos y el creciente carácter dramático de las enunciaciones. El monólogo dramático antipoético comienza con poemas/ máscaras/autorretratos en que el hablante se puede confundir y hasta identificar con el poeta. Poco a poco se van ensayando otras voces, el mendigo atracador de "Canción para correr el sombrero", Lázaro y especialmente el Cristo de Elqui, que es a la vez un personaje contradictorio e independiente del poeta y un arma para decir lo que la censura y la dictadura no permitirían. Los discursos de sobremesa son una especie de monólogo dramático también y emplean los recursos esenciales del género: un personaje hablante no necesariamente identificable con el autor/actor que se dirige a un interlocutor que no habla nunca pero que está implícito en el discurso.

Palabras clave: Monólogo dramático, antipoesía, Nicanor Parra, poesía hispanoamericana contemporánea.

\section{ABSTRACT}

The dramatic monologue, a genre developed in the nineteenth century by the English poets Robert Browning and Alfred Tennyson, is present in the antipoetry of Nicanor

* Catedrática de Literatura Hispanoamericana y Jefa del Departamento de Lenguas y Literaturas Modernas de Manhattan College, New York, USA. Correo: marlene.gottlieb@manhattan. edu 
Parra highlighting its major contributions: the opening of poetry to everyday, spoken language and to the present moment; a clear and straightforward syntax and lexicon; the replacement of the lyric Romantic subject with a character who gradually distances himself from the empirical I of the poet; the inclusion of a variety of linguistic discourses and the ever-increasing dramatic nature of the poetic enunciations. The dramatic monologue in Parra's antipoetry begins with poems that act as masks and self portraits in which the speaker can easily be confused with and even identified as the poet himself. Gradually other voices are introduced, the aggressive beggar in "Song to Pass the Hat", Lazarus, and especially the Christ of Elqui, who is a contradictory character independent of the author as well as a mechanism for eluding the censors during the Pinochet dictatorship. The After Dinner Speeches are yet another form of dramatic monologue since they use the genre's essential strategies: a speaker not necessarily identifiable with the author/actor who addresses an audience that never speaks but is implicitly included in the speech.

Key words: Dramatic monologue, antipoetry, Nicanor Parra, contemporary Hispanic American poetry.

Recibido: 20.05.12. Aceptado: 06.08.14.

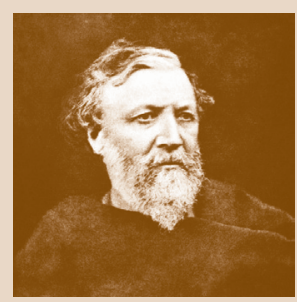

R. Browning

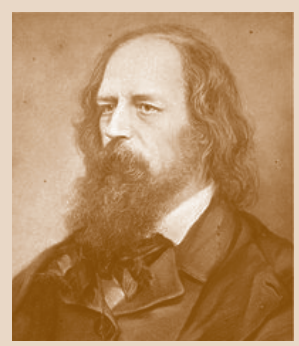

A. Tennyson
E L MONÓLOGO DRAMÁTICO es un género literario desarrollado en el siglo XIX por los poetas ingleses Robert Browning y Alfred Tennyson ${ }^{1}$. A pesar de las distintas interpretaciones del género, las características generalmente señaladas por los críticos para definir el género son las siguientes:

-El hablante es un personaje creado por el poeta.

-El personaje habla en primera persona y se dirige a un interlocutor o un público concreto.

-Se trata de un momento y un lugar específicos, muchas veces un instante crítico.

Es decir, tiene cuatro elementos esenciales: personaje hablante, oyente, lugar y circunstancia. Curry (1965 [1908]) explica estos cuatro elementos primordiales así:

To understand a monologue ... the student must first answer such questions as, Who speaks? What kind of a man says this? To whom does he

${ }^{1}$ Langbaum (1957). "The American poets, Robinson and Masters, use dramatic monologues to make us sympathize with misfits of the American scene, and Frost uses the form (often first-person narratives) to expose aberrations of mind and soul in New England. Eliot writes of asexuality and fear of life in Prufrock and Portrait of a Lady" (93). 
speak? Of whom is he talking? Where is he? At what point in the conversation do we break in upon him in the unconscious utterance of his life and motives? Then, last of all, -What is the argument? The general subject and thought will gradually become plain from the first question and the argument may be pretty clear before all the points are presented. (94-5).

All of the questions are not applicable to every monologue. Sometimes one has greater force than the others. Some monologues are given without any necessity of conceiving a distinct place; some require no definite time in the conversation; in a few the listener may be almost any one; but in some monologues every one of these questions will have force" $(95)^{2}$.

Aunque hay bastante flexibilidad en la definición del género, sin duda la característica absolutamente imprescindible es la creación de un personaje que habla en primera persona y cuenta su situación ${ }^{3}$.

Se ha señalado repetidamente que el monólogo dramático es un género que no abunda en la literatura en lengua española. Con raras excepciones ("La canción del pirata" y otras canciones de Espronceda, la del reo, del cosaco, etc.), los poetas españoles no emplean el género hasta el siglo XX y surge principalmente con los poetas de la Generación del 27. Consta nombrar "La casada infiel" de Lorca y numerosos poemas de Cernuda y Jaime Gil de Biedma. En Hispanoamérica los monólogos dramáticos más conocidos son los de Nicolás Guillén en Motivos del son (1930); el "Poema conjetural” de Borges (1943) y la primera serie de "Locas mujeres” de Gabriela

${ }^{2}$ Para entender un monólogo... el estudiante primero tiene que contestar preguntas como quién habla, qué clase de hombre es, a quién habla, de quién habla, dónde está, en qué momento de la conversación entramos para escuchar su declaración inconsciente de su vida y sus motivos? Luego, por último, ¿cuál es el argumento? El tema y pensamiento general gradualmente se elucidarán desde la primera pregunta y el argumento puede aclararse antes de que se contesten todas las preguntas.

No todas las preguntas son aplicables a todos los monólogos. A veces una tiene más fuerza que otras. Algunos monólogos se dan sin declarar un lugar específico; otros no requieren un tiempo definido en la conversación; en algunos pocos el oyente puede ser cualquiera, pero en otros monólogos cada una de estas preguntas es significativa. (Todas las traducciones del inglés son mías).

${ }^{3}$ Howe (1996) reduce su definición a un ingrediente esencial: "Identification of the speaker as someone other than the poet, whether a mythical figure like Ulysses and Tithonus, a historical one like Marvoil, or a fictional speaker such as Prufrock or the soldier of 'Locksley Hull'". "La identificación del hablante como alguien distinto del poeta, ya sea una figura mítica como Ulises o Titonio, una histórica como Marvoil, o una ficticia, como Prufrock o el soldado de 'Locksley Hull'” (3).

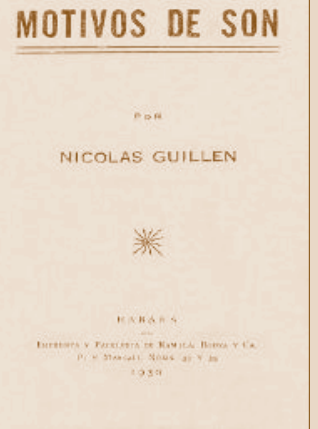



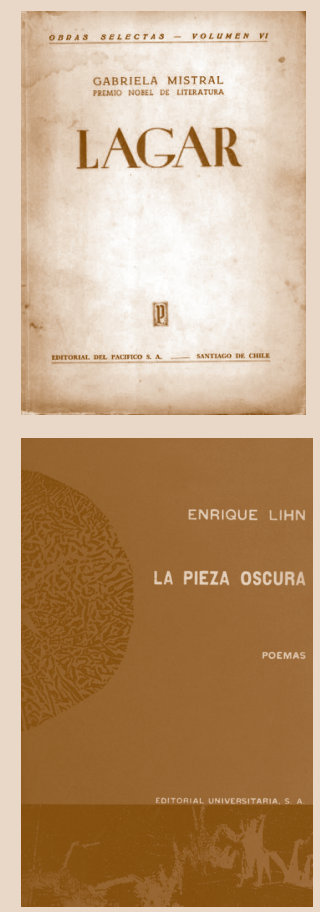

Mistral de su libro Lagar (1954)4. Hay algunos estudios muy valiosos del género en la poesía española ${ }^{5}$. Sin embargo, se ha estudiado poco el género en Hispanoamérica ${ }^{6}$, a pesar de que tiene un marcado auge en la poesía hispanoamericana a partir de los años 60. Borges emplea el género en La rosa profunda (1975) y libros posteriores (Gottlieb, 2010); Lihn en sus monólogos de La pieza oscura (1963) ("Monólogo del padre con su hijo de meses"; "Monólogo del viejo con la muerte") y los "Sonetos del energúmeno" de Por fuerza mayor (1975). Cardenal ("Proclama el conquistador" 1947; "Con Walker en Nicaragua") y Pacheco usan el género para recrear personajes históricos en su revision y reinterpretación de la historia de Latinoamérica. Asimismo el peruano Antonio Cisneros, el chileno Patricio Lerzundi, la mexicana Rosario Castellanos y el colombiano William Ospina, para nombrar solo los ejemplos más conocidos.

Nicanor Parra es uno de los poetas que más ha empleado y desarrollado el monólogo dramático en su obra y yo me atrevo a proponer que la popularidad del género en la segunda mitad del siglo XX quizás se pueda explicar en gran parte por la revolución realizada por la antipoesía de Parra. En primer lugar, el énfasis de la antipoesía en el lenguaje hablado actual y coloquial, el que ha dado lugar al término poesía conversacional ${ }^{7}$, favorece un género dramático donde el hablante literalmente habla; es una voz que se dirige a un destinatario en un lenguaje oral y directo. El papel del lector se transforma en el de espectador oyente. De hecho, en "Palabras a Tomás Lago" de Poemas y antipoemas de 1954, el hablante se refiere al "lector" como "oyente" recalcando la oralidad dramática del texto: "las personas que nos escuchan" ("Palabras a Tomás Lago").

${ }^{4}$ Hay una segunda serie de poemas no terminados del tomo Lagar II, publicado póstumamente y admirablemente estudiados por Verónika Zondek y otros. Véase Zondek (2006).

${ }^{5}$ El desarrollo del género en la poesía española ha sido estudiado por Andrew Debicki (1974), Brian Hughes (1998), Norberto Pérez García (1998), Ramón Pérez Parejo (2007), Joana Sabadell Nieto (1991), Stephen Summerhill (1989), y Akram Jawad Thanoon (1991).

${ }^{6}$ Se ha estudiado mucho menos el desarrollo del género en Hispanoamérica. Los estudios principales son los siguientes: María Rosa Olivera Williams (1996), Juan Palley (1987), Alejandro Zambra Infantas (2005). La autora de este artículo pretende realizar un estudio global del género en la poesía hispanoamericana. Este artículo sobre el monólogo dramático en la poesía de Nicanor Parra es un primer paso. Ya publiqué otro artículo sobre el monólogo dramático en la poesía de Borges (Gottlieb, 2010).

${ }^{7}$ El término "poesía conversacional” parece originarse con el artículo de Roberto Fernández Retamar (1975), "Antipoesía y poesía conversacional en Hispanoamérica. Para una teoría de la poesía hispanoamericana y otras aproximaciones” (pp. 111-126). También conviene señalar al respecto los valiosos estudios de Paul W. Borgeson (1982), "Lenguaje hablado / lenguaje poético: Parra, Cardenal y la antipoesía” (pp. 118-121,383-389) y de Carmen Alemany Bay (1997). Poética coloquial hispanoamericana. 
Aunque el monólogo dramático propiamente dicho se desarrolla al máximo en la segunda época de la obra de Parra ${ }^{8}$, i.e. a partir de Sermones y prédicas del Cristo de Elqui de 1977, los gérmenes del género ya se aprecian en los textos desde Poemas y antipoemas (1954) hasta Emergency Poems (1972). Desde los primeros antipoemas se nota la creación de un personaje hablante, característica primordial del monólogo dramático. A pesar del carácter narrativo de la antipoesía tan recalcado por los críticos ${ }^{9}$, el estudio del punto de vista de los poemas revela que la mayoría de los poemas de la primera época (i.e. antes de Artefactos 1972) están escritos en primera persona. De los 29 poemas que constituyen el tomo Poemas y antipoemas, 18 están en primera persona. La cueca larga (1957), por su misma naturaleza, tiene personajes que hablan en primera persona. En Versos de salón (1962) ocurre lo mismo. De los 30 poemas que componen el tomo, 22 están en primera persona. En Canciones rusas (1967), de 17 poemas, 11 están escritos en primera persona. En Obra gruesa (1969) y Emergency Poems (1972) pasa lo mismo: en más de la mitad de los poemas el hablante se expresa en primera persona.

En algunos de los poemas escritos en primera persona, coinciden elementos biográficos del personaje con los del poeta (el personaje es de Chillán; su madre se llama Clarisa; es poeta o profesor), y esta confusión puede quizás poner en duda la legitimidad del género ya que a pesar de que el personaje habla por sí mismo, claramente se aprecia la presencia del poeta en el trasfondo ${ }^{10}$. Esto se nota en poemas como "Autorretrato", "Epitafio" (Poemas y antipoemas); "Lo que el difunto dijo de sí mismo" (Versos de
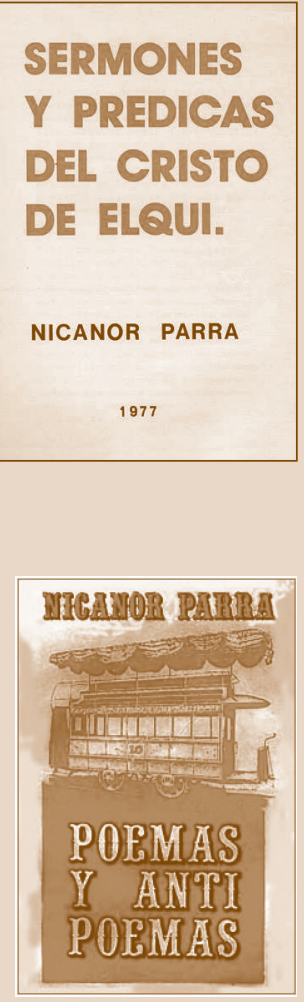

\footnotetext{
${ }^{8}$ Se puede dividir la obra de Parra en antes de 1972 y después, usando el monólogo dramático como la línea divisoria, como he hecho en mi colección de ensayos críticos Nicanor Parra: antes y después de Jesucristo. Sin embargo, un análisis más minucioso de las técnicas también justifica la división en cuatro etapas: los primeros antipoemas, los poemas reducidos al máximo, los monólogos dramáticos y los poemas objetos y performance (hasta cierto punto estas dos últimas etapas coinciden por su fecha de composición). Sin embargo, hay que recalcar que a pesar de experimentar con una nueva modalidad, Parra no abandona del todo el modelo anteriormente perfeccionado. Por lo tanto, aunque los antipoemas son cada vez más cortos desde Poemas y antipoemas a Versos de salón hasta convertirse en artefactos propiamente dichos (guatapiques, ecopoemas, chistes para despistar la poesía/policía), el antipoeta sigue componiendo antipoemas más largos, monólogos dramáticos y artefactos en la misma época en que compone los Trabajos prácticos y Obras públicas.

${ }^{9}$ Lastra et al. Conviene señalar que con estos poemas anécdotas el antipoeta introduce un sinnúmero de personajes que aunque en esta época no todos hablan en primera persona, reaparecen más adelante en monólogos dramáticos de libros posteriores.

Este es el caso de los muchos sacerdotes que pueblan la antipoesía, la figura de Dios, la Muerte y los personajes que comentan el contexto político del momento.

${ }^{10}$ Algunos críticos del género (Summerhill, Rader, Sabadell-Nieto) se refieren a este tipo de monólogo dramático como monólogo subjetivo.
} 
salón) y "Cartas del poeta que duerme en una silla" (de la sección "Otros poemas" de Obra gruesa). Sin embargo, aunque en estos textos no resulta fácil distinguir la voz del personaje hablante del yo empírico del poeta, este no es el caso de todos los poemas escritos en primera persona. En muchos casos el hablante no nos da ninguna indicación de su afiliación con el poeta y por lo tanto no tiene por qué identificarse con él. En muchos de los monólogos dramáticos de la primera época, el hablante podría representar el hombre contemporáneo, enajenado y desilusionado con la falta de valores y el materialismo del siglo XX, ese hombre tan admirablemente estudiado por Donald Shaw (2008) en su excelente libro Spanish American Poetry After 1950. Este es el caso de "El peregrino" y "Soliloquio del individuo" (Poemas y antipoemas) y tantos otros (ver tabla de categorías: personajes no necesariamente identificables y del todo identificables con el poeta). Estos poemas, entonces, por tener una especie de personaje genérico no individualizado, podríamos denominarlos precursores de los grandes monólogos dramáticos que marcan la segunda época de la antipoesía, donde ya se le da nombre, circunstancias y contexto claros al personaje.

También cabe señalar, además, que muchos de los poemas escritos en primera persona también tienen un interlocutor o un destinatario que no es el lector, otra característica del género del monólogo dramático. Cabe notar también que los frecuentes diálogos intercalados en el poema ("Sinfonía de cuna"; "Las tablas"; "Conversación galante"; "Los dos compadres") le dan un marcado carácter dramático. Incluso en los poemas escritos en tercera persona, el narrador incorpora conversaciones y escenas dialogadas.

Los poemas resultan ser escenarios con personajes que hablan y actúan ante nuestros ojos.

La antipoesía logra lo que se ha llamado la democratización de la poesía (Lastra, 1983-4: IX-XVII), i.e. todas las clases sociales se ven reflejadas en la poesía. Abre las puertas a la cultura popular. En el monólogo dramático se crea un personaje. En la obra de Parra, y en gran parte de la de los poetas posteriores, este personaje suele ser un marginado, un personaje que no ha intervenido antes en la literatura o por lo menos no ha hablado por sí mismo. El antipoeta sustituye el sujeto lírico romántico por un personaje antiheroico cuyos actos y pronunciamientos no suelen ser admirables y a veces resultan francamente despreciables ${ }^{11}$. Se trata de personajes necesita-

11 “... the tension between sympathy and moral judgment... most successful dramatic monologues deal with speakers who are in some way reprehensible. Browning's contemporaries accused him of 'perversity' because they found it necessary to sympathize with his reprehensible characters" "... la tensión entre simpatía y juicio moral... los monólogos dramáticos mejor logra- 
dos, ignorados, discriminados y hasta burlados por la sociedad. En "Epitafio" se trata de un personaje que declara que no se distingue por ninguna cualidad especial, ni por su atractivo físico ni por su inteligencia. Es un hombre común y corriente, "Ni muy listo ni tonto de remate," con características positivas y negativas, "¡un embutido de angel y bestia!”. "El peregrino" da un discurso público y como tal comienza con "Atención, señoras y señores, un momento de atención" y el personaje se describe como "un alma que ha estado embotellada durante años /en una especie de abismo sexual e intelectual" y "un árbol que pide a gritos se le cubra de hojas." Hay toda una serie de poemas, protagonizados por personajes viejos ${ }^{12}$. Suelen ser figuras tragicómicas, solitarias, que ya no cumplen un papel significativo en la sociedad y cuya actividad principal es dar de comer a las palomas en la plaza pública. Otros actúan como "viejos verdes" aunque se denominan "ancianos maduros". Otros se rebelan contra los jóvenes ("los ancianos decrépitos férreamente unidos/ haremos ver elefantes azules a los señores jóvenes iconoclastas") y contra el estereotipo del abuelo generoso y sentimental protestando: "Yo no soy un anciano sentimental/ una guagua me deja totalmente frío/ no tomaría en brazos una guagua/ aunque el mundo se estuviera viniendo abajo / .../ aborrezco las fiestas de familia".

En "Alturas de Macchu Picchu" Pablo Neruda desenterró al obrero esclavo que había construido la ciudad de Macchu Picchu y se ofreció a hablar por él, a ser el portavoz del hombre invisible a través del cual se oiría la voz del callado:

Yo vengo a hablar por vuestra boca muerta.

A través de la tierra juntad todos los silenciosos labios derramados y desde el fondo habladme toda esta larga noche como si yo estuviera con vosotros anclado, contadme todo, cadena a cadena, eslabón a eslabón, y paso a paso,

Apegadme los cuerpos como imanes.

Acudid a mis venas y a mi boca, Hablad por mis palabras y mi sangre.

dos tienen hablantes que son de alguna manera reprensibles. Los contemporáneos de Browning lo acusaron de 'perversidad' porque tuvieron que simpatizar con sus personajes reprensibles". (Langbaum, 1957, 85-6).

${ }^{12}$ EP: "Como dice Marcuse"; Yo no soy un anciano sentimental"; HP "La muerte supersónica". 
No obstante, incluso Neruda cede la palabra brevemente en la sección "La tierra se llama Juan" de Canto general en una serie de monólogos dramáticos donde los obreros mismos cuentan sus dilemas: Jesús Gutiérrez, agrarista mexicano; Luis Cortés, prisionero chileno en los campos de concentración de González Videla; Olegario Sepúlveda, zapatero de Talcahuano, Chile; Arturo Carrión, navegante de Iquique; Margarita Naranjo, salitrera de Antofogasta; y los mineros: José Cruz Achachalla, minero de Bolivia; Eufrosino Ramírez, minero de Chaquicamala; Juan Figueroa, minero de Antofogasta; el maestro Huerta, minero de Antofogasta; Amador Cea, prisionero político de Chile; Benila Varela, esposa de un prisionero político chileno. Parra lleva este proceso un paso más adelante cediéndole la palabra al marginado urbano. El poeta desaparece (o por lo menos se esconde) y aunque al principio se aprecia todavía la presencia del poeta por detrás de su personaje, más adelante, en la segunda época de la antipoesía, en obras como los Sermones y prédicas del Cristo de Elqui, el hablante no enuncia únicamente las ideas del poeta sino que se independiza del poeta y asume una identidad propia. Parra resume muy bien su intención en estos monólogos dramáticos en dos de los artefactos, obra de transición entre una y otra época de su trayectoria. Uno dice así:

Cuándo van a entender

Estos son parlamentos dramáticos

Estos no son pronunciamentos políticos

Y el otro:

El poeta es un simple locutor

El no responde por las malas noticias ${ }^{13}$

En la llamada segunda época de su obra, Parra crea personajes no solo completamente separados del poeta sino a veces hasta antitéticos. Más que individualizados y únicos, Parra opta por personajes reconocibles ${ }^{14}$, tipos que se encuentran en la vida diaria (mendigos, ladrones, viejos, un "sujeto de malos antecedentes", compadres, comerciantes, funcionarios ${ }^{15}$, estudian-

\footnotetext{
${ }^{13}$ Esta sustitución del autor por su personaje, esta desautorización y descentración del autor es una de las características que han señalado los críticos para incluir a Parra entre los autores precursores de las teorías de la posmodernidad.

${ }^{14}$ Borges hace lo mismo. Ver Gottlieb (2010).

15 “Descorcho otra botella” EP.
} 
tes ${ }^{16}$ ) o personajes históricos (Domingo Zárate Vega), literarios (Hamlet), religiosos (Dios, el Papa, miembros del clero) o simbólicos (la Muerte, que toma distintas formas tanto masculinas como femeninas).

Uno de los monólogos dramáticos más desarrollados que marca la transición a los Sermones y prédicas es "Canción para correr el sombrero", inicialmente publicado en Emergency Poems y luego incluido en otros tomos posteriores como Hojas de Parra (1985) y Poemas para evitar la calvicie (1991). El protagonista de la "Canción para correr el sombrero", como sugiere el título, es un mendigo, uno de los muchos que pueblan la poesía parriana ${ }^{17}$, pero este mendigo es un drogadicto charlatán que va contando a los convocados en la plaza la historia tragicómica de su vida y lo que lo ha llevado a su situación tan desafortunada. Es nieto desheredado de Tolstoy, su mujer le ha engañado con otro, sufre de una enfermedad incurable que lo ha dejado medio paralítico, etc. Pero cuando ve que su historia, acompañada por el trasfondo de un canto gregoriano, no produce el espíritu religioso de generosidad que pretende, cambia de táctica y agrede a sus oyentes, convirtiéndose en atracador agresivo y peligroso. Se trata de un poema inspirado en la vida urbana de los años setenta, concretamente en la estancia de Parra en la ciudad de Nueva York, en que abundaban discursos y escenas de este tipo en las plazas y espacios públicos.

Sin embargo, es en Sermones y prédicas del Cristo de Elqui (1977) y Nuevos sermones (1979) donde Parra desarrolla al máximo el monólogo dramático. Elige como protagonista un personaje histórico, Domingo Zárate Vega, el predicador ambulante del valle de Elqui que vivía en los años treinta durante la dictadura del general Carlos Ibáñez del Campo (1927-3) ${ }^{18}$. Apodado el Cristo de Elqui por los sermones y folletos que distribuía entre los pobres, por su voto de castidad y pobreza, por su barba larga y su humilde sayal, es un personaje idóneo para las intenciones del antipoeta. En primer lugar, a pesar de llamarse Cristo, es "hombre y no dios como creen algunos," como explica en el sermón III. Es pobre, de padre cesante y madre enferma, se expresa en lenguaje vulgar explicando que "esa es la lengua de la gente" (IX). En fin, es "más chileno que el mote con huesillos" (XXVII). Extravagante y algo payaso, lleva más de veinte años cumpliendo la manda que hizo a la muerte de su madre de no cortarse ni la barba ni las uñas. Sus amigos son:

\footnotetext{
16 "Los profesores" 1971.

17 “Mendigo" CR, "Proposiciones” EP.

${ }^{18}$ Luego fue presidente de la República elegido entre 1952-1958.
} 
los enfermos

los débiles

los pobres de espíritu

los que no tienen donde caerse muertos

los ancianos

los niños

las madres solteras

-los estudiantes no porque son revoltosos-

los campesinos porque son humildes

los pescadores

porque me recuerdan

a los santos apóstoles de Cristo

los que no conocieron a su padre

los que perdieron como yo a su madre

los condenados a cadena perpetua

en las llamadas oficinas públicas

los humillados por sus propios hijos

los ofendidos por sus propias esposas

los araucanos

los postergados una y otra vez

los que no saben ni siquiera firmar

los panaderos

los sepultureros (XXXII)

Y como ellos, es víctima de "humillaciones, calumnias, desprecios". Hasta los sacerdotes se mofan de él poniendo en duda su virilidad.

Los dos tomos de Sermones y prédicas constan de 63 sermones y en muchos poemas Parra le da libertad a su personaje de hacer declaraciones "propias," aunque muchas revelan el humor burlesco y a veces blasfemo de su progenitor. Como figura religiosa popular, interpreta la Biblia y las oraciones:

Lo primero la madre padres pueden haber en cantidades técnicamente hablando nadie puede decir este es mi padre este señor es mi progenitor a ciencia cierta no se sabe nada seguridad no hay en estas cosas sin ofender a nadie en particular el $50 \%$ por lo menos algo que no sucede con la madre siempre se sabe quién es nuestra madre 
es por esto que yo no digo nunca

padre nuestro que estás en el cielo;

con el perdón del respetable público

me parece más atinado decir

madre nuestra que estás en el cielo

santificado sea tu nombre... (LXII)

Critica el comportamiento de los sacerdotes lascivos:

Los compadezco pero me dan asco si no tienen control sobre sí mismos deberían colgar la sotana (XXI)

y da consejos a los maridos:

Los maridos debieran seguir un curso por correspondencia si no se atreven a hacerlo personalmente sobre los órganos genitales de la mujer hay una gran ignorancia al respecto

sin embargo se consideran con derecho a casarse como si fueran expertos en la materia resultado: problemas conyugales adulterio calumnias separación ¿y cómo quedan esos pobres hijos? (VII)

Además, a través del personaje del Cristo de Elqui, Parra logra comentar el momento actual, i.e. la dictadura de Pinochet, eludiendo así la censura ya que insiste en la independencia del personaje de su creador, como es la norma del género del monólogo dramático y declarando, como tantas veces lo ha hecho, que no se le puede culpar a Cervantes de las groserías de Sancho (véase Lerzundi, 1972: 65-71). La crítica a la dictadura militar es patente, aunque no explícita sino escondida entre otros versos más blasfemos que políticos:

Y estos son los desafíos del Cristo de Elqui:

que levanten la mano los valientes:

a que nadie se atreve

a tomarse una copa de agua bendita

Y así sigue con una larga enumeración de actos atrevidos para concluir 
con estos versos que a la vez que afirman su patriotismo fervoroso, critican la situación en Chile:

a que nadie es capaz

de arrancarle una hoja a la biblia

ya que el papel higiénico se acabó

a ver a ver a que nadie se atreve

a escupir la bandera chilena

primero tendría que escupir mi cadáver

apuesto mi cabeza

a que nadie se ríe como yo

cuando los filisteos lo torturan (XXIII)

Otro sermón encubre la crítica a través de una serie de distracciones y falsas aclaraciones. Empieza el poema como si fuera a contar la conquista de Chile, pero pronto intercala versos subversivos; se protege de la censura por su referencia a la dictadura del general Ibáñez del año 1929, poniéndose así a salvo para que no puedan acusarle de estar denunciando la situación actual, aunque la alusión está implícita. Además al final suaviza la crítica generalizándola a todos los países del mundo:

Cuando los españoles llegaron a Chile se encontraron con la sorpresa de que aquí no había oro ni plata nieve y trumao sí: trumao y nieve nada que valiera la pena los alimentos eran escasos y continúan siéndolo dirán ustedes es lo que yo quería subrayar el pueblo chileno tiene hambre sé que pronuncir esta frase puedo ir a parar a Pisagua pero el incorruptible Cristo de Elqui no puede tener otra razón de ser que la verdad el general Ibáñez me perdone en Chile no se respetan los derechos humanos aquí no existe libertad de prensa aquí mandan los multimillonarios el gallinero está a cargo del zorro claro que yo les voy a pedir que me digan en qué país se repetan los derechos humanos (XXIV) 
Es difícil, además, tomar sus pronunciamientos en serio ya que se contradice. En un sermón alaba al comunista Recabarren (LXI); en otro se burla de los socialistas:

Si realmente fueran socialistas

Un monumento para cada mortal

O ningún monumento para nadie (XXXVI)

y en otro asume la voz de la oligarquía chilena haciendo eco de las recomendaciones del argentino Sarmiento:

¡Este país es una buena plasta!

i¡Aquí no se respeta ni la ley de la selva!!

"ya levantaremos cabeza" "ya levantaremos cabeza"

¡cuándo vamos a levantar cabeza

si descendemos de indios borrachos

y de una cáfila de españoles aventureros

delincuentes comunes en su mayoría!

iiel 32 de diciembre de mil novecientos nunca!!

¡sangre sajona es lo que falta aquí

para contrarrestar al indio ladrón e indolente! (LI)

En el próximo libro, Hojas de Parra, el título mismo recalca la double entendre antipoético: son páginas del poeta Parra y a la vez hojas que tapan "lo que no se debe ver". Este tomo contiene varios monólogos dramáticos. Dos poemas que se complementan y hasta parecen dialogar entre sí son "El anti-Lázaro" y "Descansa en paz". Otra vez Parra ha vuelto a personajes no demasiado individualizados y distintivos; se trata de personajes algo "genéricos" que desmitifican ciertas historias o conceptos populares. En el primer poema, en una revision actualizada de la historia bíblica, el hablante es un viejo amigo de Lázaro que le recomienda en un lenguaje muy chileno y coloquial que no resucite ya que su vida era desastrosa y no tiene ningún sentido repetirla: "a qué volver entonces al infierno de Dante / ¿para que se repita la comedia?", concluyendo:

No resucites por ningún motivo no tienes para qué ponerte nervioso como dijo el poeta tienes toda la muerte por delante (135)

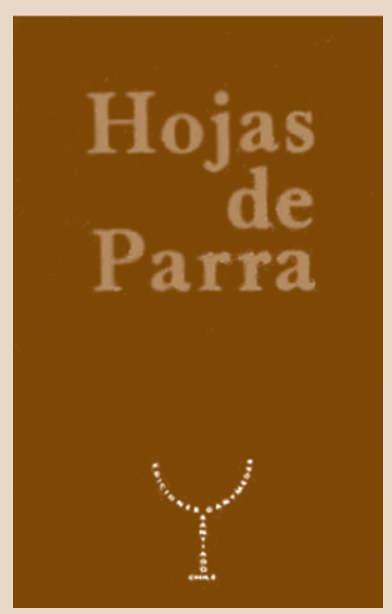


En el segundo poema, que resulta ser una especie de contestación y contraparte al primero, Parra toma la frase retórica "descansa en paz" y hace que su personaje cadáver la cuestione y la ridiculice presentándose como un muerto vivo que se enfrenta con una serie de tribulaciones físicas con las que tiene que luchar en su "muerte diaria":

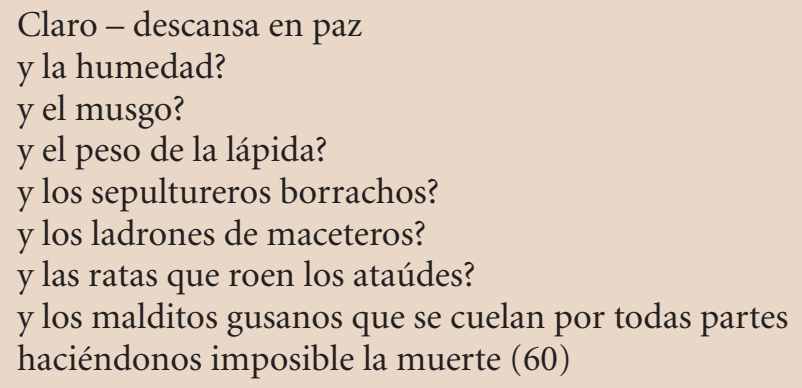

Otro monólogo dramático de Hojas de Parra es "Poemas del Papa" en que el antipoeta desmitifica la figura del Papa presentándolo no como un ser desinteresado y superior, intérprete mayor de la religion católica, sino como un hombre común y corriente que se expresa como cualquier persona de clase media con problemas y rasgos semejantes a los de su grey: envidias, ambiciones. orgullo, egoísmo:

3

Los Cardenales están molestos conmigo porque no los saludo como antes ¿demasiado solemne? es que soy el Papa caramba

4

Mañana a primera hora me traslado a vivir al Vaticano

5

Tema de mi Discurso:

Como triunfar en la Carrera Eclesiástica (92-3)

Después de los dos tomos de Sermones y prédicas y los monólogos dramáticos de Hojas de Parra, el antipoeta experimenta con otro género afín: el discurso de sobremesa. Aquí el poeta asume el papel de orador y discurre sobre un tema, muchas veces literario, como es el caso de Juan Rulfo en "Mai mai peñi” y de Vicente Huidobro en "Also Sprach Zaratustra”. El 
poeta autor es reemplazado por el poeta actor que hace el papel de orador y este orador, rompiendo con todas las normas, desacraliza el género y lo convierte en una especie de teatro muy afín al monólogo dramático. Los discursos de sobremesa son una especie de género híbrido entre el monólogo dramático y el espectáculo (véase Gottlieb, 1996: 71-94) donde el poeta asume el papel de actor-orador empleando muchos de los recursos del monólogo dramático (un personaje hablante que se dirige a un "interlocutor", el público oyente, que no habla nunca pero cuya respuesta o reacción está implícita en el discurso), pero más que texto en lenguaje oral, el discurso de sobremesa es teatro. Parra ha dejado atrás el monólogo dramático propiamente dicho y ha pasado a la obra espectáculo, al "performance" ya sea en forma de discursos de sobremesa o en forma de objets trouvés a lo Marcel Duchamp (Trabajos prácticos).

Para resumir, el monólogo dramático es un género muy desarrollado en la antipoesía. Parra comienza con poemas en que el hablante se puede confundir y hasta identificar con el poeta para luego ensayar otras voces y personajes contradictorios e independientes del poeta. El monólogo dramático se convierte en un arma para decir lo que la censura y la dictadura no permitirían y a la vez para comentar el momento actual, "saltando a papirotazos los cimientos apolillados" como tan elocuentemente resumió Parra la misión del antipoeta en su "Discurso de bienvenida a Pablo Neruda" de 1962. El impacto del monólogo dramático sigue vigente, quizás impulsado por la obra de Parra, en varios poetas de la segunda década del siglo XX como Pacheco, Cisneros, Gelman, Kozer, Bolaño y muchos otros. El desarrollo del monólogo dramático en la poesía hispanoamericana es un campo abierto que todavía requiere mucho estudio.

\section{REFERENCIAS}

Alemany Bay, C. (1997). Poética coloquial hispanoamericana. Alicante: Universidad de Alicante.

Borgeson, P. W. (1982). "Lenguaje hablado / lenguaje poético: Parra, Cardenal y la antipoesía". Revista Iberoamericana 118-121, 383-389.

Curry, S.S. (1965 [1908]). Browning and The Dramatic Monologue. New York: Haskell House.

Debicki, A. P. (1974). "Satire and Dramatic Monologue in Several Poems of Damaso Alonso". Books Abroad 48, 276-85.

Fernández Retamar, R. (1975). "Antipoesía y poesía conversacional en Hispanoamérica. Para una teoría de la poesía hispanoamericana y otras aproximaciones". La Habana: Casa de las Américas, pp. 111-126. 
Gottlieb, M. (1996). “Nicanor Parra o el método del discurso”. Atenea 473, 7194.

(2010). “The Dramatic Monologue in the Poetry of Jorge Luis Borges”. Variaciones Borges 30, 59-81.

Howe, E. A. (1996). The Dramatic Monologue. New York: Twayne.

Hughes, B. (1998). Luis Cernuda and the Modern English Poets: A Study of the Influence of Browning, Yeats, and Eliot on his Poetry. Murcia: Universidad de Alicante.

Jawad Thanoon, A. (1991). El monólogo dramático en la poesía española contemporánea. Granada: Universidad de Granada.

Langbaum, R. (1957). The Poetry of Experience. New York: Norton.

Lastra, P. (1983-4). "Notas sobre la poesía hispanoamericana actual”. INTI 1819, ix-xvii.

Lerzundi, P. (1972). "Interview with Nicanor Parra". Review 4-5, 65-71.

Neruda, P. (1962). Obras completas. Buenos Aires: Losada.

Olivera Williams, M. R. (1995). "Retórica de la experiencia en Personas del verbo de Jaime Gil de Biedma”. Revista Hispánica Moderna XLVIII, 1, 171-80.

(1996). "El monólogo dramático en la poesía de José Emilio Pacheco”. Revista Iberoamericana LXII, 174, 175-84.

Palley, J. (1987). "El monólogo dramático en la poesía de Rosario Castellanos". Evaluación de la literatura femenina de Latinoamérica, siglo XX. II Simposio Internacional de Literatura. Tomo II. San José: Editorial Centroamericana (EDUCA).

Parra, N. (1962). Discursos. Santiago: Nascimento. (2006 y 2011). Obras completas \& algo + (1935-1972) y (1975-2006). Barcelona: Círculo de Lectores Galaxia Gutenberg.

Pérez García, N. (1998). “Antecedentes españoles decimonónicos del monólogo dramático: La poesía de Gaspar Núñez de Arce”. En Garrido Gallardo, A., Estudios de literatura española de los siglos XIX y XX: Homenaje a Juan María Díez Taboada. Anejos de Revista de Literatura 47. Madrid: Consejo Superior de Investigaciones Científicas, 336-41.

Pérez Parejo, R. (2007). "El monólogo dramático en la poesía española del XX: ficción y superación del sujeto lírico confesional del Romanticismo”. Espéculo. Revista de estudios literarios. Universidad Complutense de Madrid. Disponible en: http://www.ucm.es/info/especulo/numero36/monodram. html

Rader, R. W. (1976). “The Dramatic Monologue and Related Literary Forms”. Critical Inquiry 3, 131-151.

Sabadell Nieto, J. (1991). "El monólogo dramático. Entre la lírica y la ficción”. Tropelías: Revista de Teoría de la Literatura y Literatura Comparada 2, 17786.

Shaw, D. (2008). Spanish American Poetry After 1950. London: Tamesis.

Summerhill, S. (1989). "Luis Cernuda and the Dramatic Monologue”. En Jimé- 
nez-Fajardo, S. (ed.). The Word and the Mirror: Critical Essays on the Poetry of Luis Cernuda (pp. 140-165). Rutherford, NJ: Fairleigh Dickinson UP.

Zambra Infantas, A. (2005). "Sobre el monólogo dramático (Ilustración en el Poema conjetural de Borges)”. Revista de Literatura LXVII: 143, 547-54.

Zondek, V. (2006). "Las locas mujeres de Gabriela Mistral”. Documentos Lingüísticos y Literarios No 29. Disponible en: http://www.humanidades.uach. cl/documentos_linguisticos/document.php?id=1303 